\title{
Handverjüngung gegen die Spuren der Zeit
}

\author{
Mit 60 die Hände einer 30-Jährigen zu haben, ist Dank neuer dermatologischer Techniken kein \\ unerfüllbarer Traum mehr. Wir haben mit der Kölner Dermatologin Dr. Uta Schlossberger über die \\ diversen Verjüngungsmethoden gesprochen.
}

\section{$?$}

Dr. med. Uta Schlossberger Niedergelassene Fachärztin für Dermatologie und Venerologie in Köln

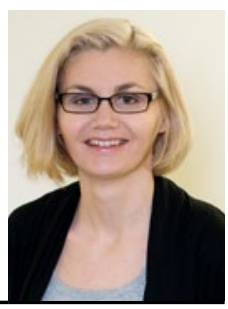

MMW: Wie verändern sich die Hände im Alter?

Schlossberger: Einerseits haben wir den Kollagenabbau, der ja auch an anderen Hautstellen stattfindet. Zudem geht subkutanes Fettgewebe verloren, was zum Bild der Knochenhände führt. Hinzu kommen äußerliche Veränderungen der Haut wie Sonnenflecken, die Haut wird trocken und es zeigen sich Fältelungen.

\section{MMW: Welche Therapien bieten Sie an?}

Schlossberger: Grundsätzlich richten wir uns nach den Wünschen der Patienten. Wenn jemand nur eine Laserbehandlung oder ein Peeling für die Pigmentflecken

\section{Skinbooster}

Skinbooster wurden zur Tiefenhydratation der Haut entwickelt. Die injizierten leichten Hyaluronsäuren nehmen viel Wasser auf und sorgen damit für lang anhaltende Feuchtigkeit. Indem körpereigene Speicher in tiefen Hautschichten wieder aufgefüllt werden, verbessern sich Struktur, Straffheit und Elastizität, und es entsteht ein gesundes und strahlendes Hautbild. Neben den Händen können vor allem auch Gesicht, Hals und Dekolleté mit dieser Methode verjüngt werden. möchte, erhält er das. Wenn ich aber merke, dass die Patienten ganz offen sind, erkläre ich ihnen natürlich, dass wir mit einer Kombinationstherapie erreichen könnten, dass die Hände wieder wie mit 30 oder 35 Jahren aussehen.

\section{MMW: Wie sieht das Gesamtpaket} zur Rejuvenation der Hände aus?

Schlossberger: Für den Handrücken stehen verschiedene Filler zur Verfügung. Je

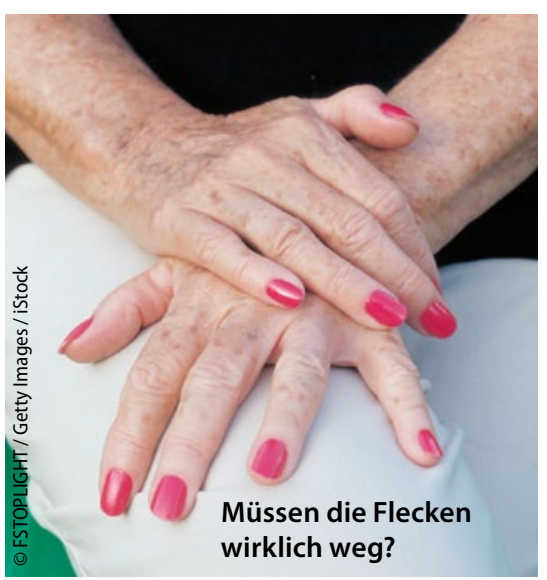

nach dem verwendeten Material reicht das Ergebnis von einem Rejuvenationseffekt mit einem guten Hautbild bei leichter Füllung bis hin zu einem stärkeren Volumen. Mit Makrolane etwa hat man früher richtige „Patschehände“ erhalten. Auch Eigenfett macht Hände sehr voluminös. Neben dem Volumen sollte die Straffheit verbessert und das Gesamtbild der Haut beachtet werden. Sie soll nach der Behandlung wieder einen gewissen "Glow“ haben, die kleinen Knitterfältchen, Sonnenflecken und Pigmentstörungen sollten verschwunden sein.
MMW: Wie werden Pigmentflecken beseitigt?

Schlossberger: Wir verwenden hierzu einen Farbstofflaser. Gegenüber den Peelings hat das u. a. den Vorteil, dass damit nur einmal behandelt werden muss.

MMW: Welchen Filler empfehlen Sie zum Ausgleich des altersbedingten Volumenverlusts?

Schlossberger: Heute gibt es sehr leichte Filler, sog. Skinbooster, die eine gute Wirkung auf die Hautstruktur haben. Die Haut wird feiner und beginnt mehr Wasser aufzunehmen. Hyaluronsäure hat, anders als Eigenfett, die Eigenschaft, bis zu sechs Liter Wasser pro Gramm anzuziehen. Damit gelangen auch mehr Vitamine und Mineralien in die Haut. So erreicht man mit leichten Fillern wirklich einen Rejuvenationseffekt. Ein weiterer Vorteil: Während eine Eigenfettbehandlung sechs Monate hält, müssen leichte Filler frühestens nach acht Monaten erneut gespritzt werden.

MMW: Lassen sich auch Männer die Hände verjüngen?

Schlossberger: In den letzten Jahren sind die männlichen Patienten in der ästhetischen Dermatologie allgemein von 10 auf etwa $30 \%$ gestiegen. Bei den Händen schätze ich ihren Anteil sogar mittlerweile auf 40\%. Allerdings stören sich Männer ausschließlich an den Hyperpigmentierungen der Hände. Sonnenflecken, Augenringe und die „Zornesfalte“ sind für die Männer die wichtigsten Gründe, einen ästhetischen Dermatologen aufzusuchen.

Interview: Dr. Christine Starostzik 